\title{
An attempt to increase efficacy of doxorubicin against MCF-7 cells by using nanotechnology
}

\author{
M.D. Imad Uddin * and B. Veeresh** \\ Department of Pharmacology, Pulla Reddy Institute of Pharmacy, Hyderabad-502313, Telangana State, India \\ *Department of Pharmacy, University College of Technology, Osmania University, Hyderabad-500007, Telangana State, India \\ **Department of Pharmacology, G. Pulla Reddy College of Pharmacy, Hyderabad-500028, Telangana State, India
}

\section{Article Info}

Article history

Received 10 October 2021

Revised 27 November 2021

Accepted 29 November 2021

Published Online 30 December 2021

Keywords
Chitosan
FTIR
Particle size
Zetapotential
SEM
MTT assay
Anticancer activity

the particle size as $172 \mathrm{~nm}$ and $174 \mathrm{~nm}$ for PLN-CNPs-3 and DRN-CNPs-1 NPs. DRN-CNPs are further
evaluated for release of the drug, encapsulation, and loading efficiency. After $60 \mathrm{~h}$, more than $50 \%$ of the
drug was released from the formulation. Encapsulation efficiency, loading efficiency, and \% yield of DRN-
CNPs- 1 were found to be $78.5 \%, 13.8 \%$, and $35.7 \%$, respectively. Debye-Scherrer equation was applied for
$2 \theta$ peaks obtained from XRD data of DRN-CNPs-1 to calculate average particle size (30.50 nm). Anticancer
activity of DRN-CNPs-1 was compared with unloaded DRN against MCF-7 cell lines. It was dose dependent
in both treatments and DRN-CNPs-1 was found to be more effective than DRN. This research put forth an
idea to use chitosan a biocompatible polymer for loading anticancer drugs like DRN to increase their
efficacy.

\section{Introduction}

Cancer is a dreadful disease, characterized by the development of benign or malignant tumors from the cells which escape the normal death process and continue to divide without control. It is of many types based on location and based on pathophysiology. It was first identified in the $16^{\text {th }}$ century and was considered a challenging disease to mankind around the world and till the $19^{\text {th }}$ century, no cure was identified for cancer (Han et al., 2006).Till the middle of the $19^{\text {th }}$ century, surgery was considered as the first line of treatment for many types of cancer, but later on discovery of nitrogen mustard laid the path for chemotherapeutic treatment (Papac, 2001). By considering financial and social burden of cancer on humanity research around the world focused on discovering various modes of treatment. Cryotherapy, chemotherapy, hormonal therapy radiation therapy, and gene therapy are some of the commonly discovered

Corresponding author: Mr. M.D. Imad Uddin
Associate Professor Department of Pharmacology, Pulla Reddy Institute
of Pharmacy, Hyderabad-502313, Telangana State, India
E-mail: imadpharma111 @ gmail.com
Tel.: +91-8374175556
Copyright () 2021 Ukaaz Publications. All rights reserved. Email: ukaaz@yahoo.com; Website: www.ukaazpublications.com advanced modes of treatment for cancer (American Cancer Society, 2019). Despite many treatment options, cancer mortality remains a challenge. According to the WHO, cancer fact sheet dated 21 September 2021, about 1 crore people around the world died due to different types of cancer in 2020. Breast cancer was found to be most prevailing type with 22.6 lakh new cases in 2020 (World Health Organization, 2021). Similarly, lung cancer was also found to be prevailing at the same rate as that of breast cancer, i.e., affecting around 22.1 lakh people in 2020. Therefore, cancer remains a major challenge to be addressed in the healthcare system and specifically with an emergency call of breast and lung cancer management.

DRN is a well-known anticancer drug belonging to the anthracycline family (Prados, 2012). DRN is widely used as a first-line drug for treatment of breast cancer. It acts by blocking the topoisomerase-II enzyme. As this enzyme is inhibited DRN successfully blocks DNA replication. It also acts by getting intercalated into DNA. Thus, by these two mechanisms, it is successfully producing antimitotic and cytotoxic activity by inhibiting gene expression and producing oxidative stress in the form of generation of reactive oxygen species (Chatterjee, 2010). A major challenge in use of DRN is the development of drug resistance. Apart from this, it is also presented with 
severe cardiac related problems, bone marrow related abnormalities, and attacking normal cells along with cancer cells. These all problems should be addressed to increase the use of this established anticancer drug. The discovery of nanotechnology appeared as a boon for the treatment of many diseases.

For a few decades, researchers throughout the world showed a keen interest in nanotechnology. Different types of NPs like inorganic NPs, e.g., quantum dots, gold NPs, etc., organic NPs, e.g: dendrimers, micelles, etc., and hybrid NPs, e.g: lipid-polymer hybrid NPs, etc., are reported to improve anticancer activity of different chemotherapeutic agents (Yao et al., 2020). Requirement of low dose, targeted delivery and increased bioavailability are some of the important benefits of using NPs loaded drug delivery systems (Zhang et al., 2016). Poly (lactide-co-glycolide), poly (lactide), alginate, albumin, chitosan is some of the commonly used polymers for preparation of NPs. Therefore, this research was carried out in an attempt to optimize the best suited concentration of chitosan and STTP for the synthesis of DRN loaded NPs. These DRN NPs are evaluated for their anticancer efficacy against MCF-7 cells.

\section{Materials and Methods}

\subsection{Chemicals and cell lines}

Chitosan was used as a polymer for loading DRN, obtained from Vihan life sciences, Ahmednagar, India. A cross linker sodium tripolyphosphate, sodium hydroxide, and hydrochloric acid were obtained from SD Fine Chemicals Limited, Mumbai, India. Doxorubicin-an anticancer drug was obtained from Sigma Aldrich, Icon Biosystems, Hyderabad, India. Breast cancer cell line MCF-7 cells were obtained from the National Center for Cell Sciences (NCCS), Pune.These MCF-7 cells are cultured according to the standard protocol as follows. These cells are cultured in a minimum essential medium containing a higher concentration of essential nutrients. An experiment was carried out at $37^{\circ} \mathrm{C}$ and used $5 \%$ of $\mathrm{CO}_{2}$.

\subsection{Methods}

\subsubsection{Characterisation of DRN}

DRN procured was further characterized by using different techniques. A saturated solubility study was conducted by using the shake flask method with different solvents, viz., distilled water, DMSO, ethanol, $0.1 \mathrm{M} \mathrm{HCl}, 0.1 \mathrm{M} \mathrm{H}_{2} \mathrm{SO}_{4}, 6.8$, and $8.4 \mathrm{PBS}$. About 2 $\mathrm{ml}$ of each solvent was taken in a glass vial. After adding an excess amount of drug to each solvent, mouth was closed. These closed vials are shaken on an orbital shaking incubator for $48 \mathrm{~h}$ equipment was set to rotate at $50 \mathrm{rpm}$ and maintained at a temperature of $37^{\circ} \mathrm{C}$. At the end of $48 \mathrm{~h}$, solution is centrifuged and the clear supernatant was collected. This is diluted further in the respective solvent system and absorption was taken by using UV-visible spectroscopy at solvent respective $\lambda$ max. Finally, absorption of drug is converted to concentration by using standard curve of DRN in the respective solvent.

$\lambda \max$ of DRN was estimated by measuring absorption on UV spectroscopy (Lab India-UV3000) operated in the range of 200$600 \mathrm{~nm}$. Later on, about $10 \mathrm{ml}$ of DRN stock solution of concentration $1 \mathrm{mg} / \mathrm{ml}$ is produced in distilled water. By using this stock solution, $3,6,9,12$, and $15 \mu \mathrm{g} / \mathrm{ml}$ solutions are prepared which are used to obtain a calibration curve at $232 \mathrm{~nm}$. For FTIR analysis, a minute quantity of DRN was taken in a microspatula and 0.40 teaspoons of $\mathrm{KBr}$ was added. This was mixed thoroughly by using motor and pestle. This mixture is pressed at 5000-10000 psi to obtain a pellet. This pellet was analysed for the presence of functional groups by using an FTIR spectrophotometer (Bruker, Alpha) operated in the range from 4000 to $500 \mathrm{~cm}^{-1}$. In addition to DRN, FTIR analysis was also carried out for chitosan, STTP, physical mixture of chitosan and STTP; DRN, chitosan and STTP. The melting point was measured by using the capillary tube method. DRN was taken up to a height of $3 \mathrm{~mm}$ in one side closed capillary tube. This capillary tube is placed in melting point apparatus (Bio Technics, India) to analyze the sample.

\subsubsection{Synthesis and characterization of PLN-CNPs and DRN- CNPs}

\subsubsection{Synthesis of PLN-CNPs and DRN-CNPs}

$25 \mathrm{ml}$ of low molecular weight chitosan solution $(0.5 \mathrm{mg} / \mathrm{ml})$ was prepared by dissolving $12.5 \mathrm{mg}$ of chitosan in $25 \mathrm{ml}$ of $1 \%$ acetic acid and $\mathrm{pH}$ was adjusted to 4.7 by adding $1 \mathrm{M} \mathrm{NaOH}$ solution. Similarly, $25 \mathrm{ml}$ of STPP solution $(0.7 \mathrm{mg} / \mathrm{ml})$ was prepared by dissolving $17.5 \mathrm{mg}$ of sodium tripolyphosphate (STTP) in $25 \mathrm{ml}$ of distilled water, and $\mathrm{pH}$ was adjusted to $2 \mathrm{using} 1 \mathrm{M} \mathrm{HCl}$.

In this study, to optimize the best suited concentration of chitosan, STTP, and DRN for preparing NPs, a range of PLN-CNPs and DRNCNPs are prepared. Both of these NPs are prepared by a slight modification of the ionic gelation method reported by Othman et al. (2018). Five different formulations, 1, 2, 3, 4, and 5 of PLNCNPs were prepared by adding $600 \mu \mathrm{l}$ of chitosan solution to 100 , 200, 300, 400 and $500 \mu \mathrm{l}$ of STPP solution, respectively. DRNCNPs were prepared in two steps: In the first step, the range of DRN-STTP solutions (formulation 1, 2, and 3) were prepared by adding 500,1000 , and $1500 \mu \mathrm{g} / \mathrm{ml}$ of DRN to $300 \mu \mathrm{l}$ of above prepared STTP solution, respectively. In the second step, $600 \mu 1$ of chitosan was added to the above prepared DRN-STTP solutions to make DRN loaded CNPs.

\subsubsection{Particle size, PDI, zeta potential and EMM estimation of PLN-CNPs and DRN-CNPs}

PDI, particle size and stability of solution (zeta potential) were determined for all the above prepared PLN-CNPs (formulation 1 to 5) and DRN-CNPs (formulation 1 to 3 ) by using Horiba-SZ-100 zeta sizer. For measurement of particle size and PDI instrument was operated with scattering angle of $90^{\circ} \mathrm{C}$, the temp of holder was $25^{\circ} \mathrm{C}$, the viscosity of dispersion medium was $2.035 \mathrm{mPa} . \mathrm{s}$, representation of result by scattering light intensity method, and count rate was $342 \mathrm{kCPS}$. Whereas for measurement of zeta potential and EMM, zeta sizer was operated with a temperature of the holder at $25^{\circ} \mathrm{C}$, the viscosity of dispersion medium was $0.893 \mathrm{mPa}$.s, conductivity was $0.221 \mathrm{mS} / \mathrm{cm}$, and electrode voltage was $3.3 \mathrm{~V}$. All these data of particle size and PDI are analyzed by Pareto analysis in Microsoft excel-2019 to obtain the best formulation for further study. The best selected formulation is further analysed by FTIR and SEM analysis.

\subsubsection{FTIR and SEM analysis of PLN-CNPs and DRN-CNPs}

Functional groups present in these PLN-CNPs and DRN-CNPs were determined by FTIR analysis (Shimadzu-8400S). FTIR spectrometer 
was operated with a working range of 4000 to $500 \mathrm{~cm}^{-1}$, no. of scans was 10, a resolution was $4 \mathrm{~cm}^{-1}$ and apodization was done by square triangle method. Morphological features of PLN-CNPs and DRN-CNPs were determined by using a scanning electron microscope (SEM) (Hitachi-S3700N) operated at a magnification of $2 \mathrm{~K}$ to $8 \mathrm{~K}$, acceleration voltage of $30 \mathrm{KV}$, emission current of $100000 \mathrm{nA}$, and working distance of 9.1 to $9.2 \mathrm{~mm}$. Best selected DRN-CNPs are further characterized for in vitro drug release efficiency, encapsulation efficiency, loading efficiency, XRD analysis.

2.2.3 In vitro drug release, encapsulation efficiency, loading efficiency, and \% yield estimation of DRN-CNPs
For evaluating in vitro drug release, $10 \mathrm{mg}$ of DRN-CNPs was suspended in $1000 \mu \mathrm{l}$ of PBS $(\mathrm{pH}=7.4)$. This suspension was taken in a dialysis bag (cut-off molecular weight of dialysis membrane was $10000-12000 \mathrm{Da}$ ). The bag was immersed in a $5 \mathrm{ml}$ PBS $(\mathrm{pH}=7.4)$ and incubated at $37^{\circ} \mathrm{C}$. At $0,20,40,60,80$ and $100 \mathrm{~h}$ about $5 \mathrm{ml}$ of release medium was withdrawn and $5 \mathrm{ml}$ of fresh PBS was added. The amount of drug released in the medium was estimated at $232 \mathrm{~nm}$ by using UV Vis spectrophotometer. For screening encapsulation efficiency, loading efficiency, $1 \mathrm{ml}$ of DRNCNPs is centrifuged. The absorbance of the supernatant was obtained at $232 \mathrm{~nm}$. Formulas used as follows:

$$
\begin{aligned}
& \mathrm{EE} \%=\left(\frac{\text { Total drug used for NP preparation - Free drug present }}{\text { Total drug used for NP preparation }}\right) \times 100 \\
& \mathrm{LE} \%=\left(\frac{\text { Total drug used for NP preparation - Free drug present }}{\text { Yeild of NPs }}\right) \times 100 \\
& \% \text { Yield of NPs }=\left(\frac{\mathrm{W}_{1}}{\mathrm{~W}_{2}}\right) \times 100
\end{aligned}
$$

where as $\mathrm{W}_{1}=$ Dried Wt. of NP's, $\mathrm{W}_{2}=$ Wt. of drug + Wt. of STPP + Wt. of Chitosan.

\subsubsection{XRD analysis of DRN-CNPs}

To identify the phase and to assess the crystallographic structure of the purified DRN-CNPs, XRD studies were carried out. XRD instrument was operated at a voltage of $40 \mathrm{kV}$ and a current of 30 $\mathrm{mA}$ with $\mathrm{K} \alpha 1 \mathrm{Cu}$ radiation, $\lambda=1.54 \AA$ with nickel monochromator in the $2 \theta$ range from $10^{\circ}$ to $80^{\circ}$. In order to carry out XRD analysis, $100 \mu \mathrm{l}$ of DRN-CNPs was applied as a thin film on a glass slide and allowed to dry for $30 \mathrm{~min}$ and subjected to diffraction studies. The average size of NPs was assessed by using the Debye-Scherrer equation.

$$
\mathrm{D}=\left(\frac{\mathrm{K}}{\beta \cos \theta}\right)
$$

where $\mathrm{D}=$ average size of DRN-CNPs, $\mathrm{k}=$ constant $(0.94), \beta=$ wavelength of $\mathrm{X}$ - rays $(0.1546 \AA), \beta=$ full width at half maximum, $\theta=$ diffraction angle in degrees.

\subsubsection{In vitro anticancer activity of plain DRN and DRN-CNPs against MCF-7 cells}

MCF-7 cells were plated at a density of $5 \times 10^{3}$ cells per well in a 96 well plate which was supplemented with $10 \%$ FBS. This is incubated for $24 \mathrm{~h}$ at $37^{\circ} \mathrm{C}$ and $5 \% \mathrm{CO}_{2}$. These cells were treated with vehicle, pure DRN, and DRN-CNPs for $48 \mathrm{~h}$. Cell viability was determined by adding $100 \mu \mathrm{l}$ of 3-(4,5-Dimethyl-2-thiazolyl)-2,5-diphenyl$2 \mathrm{H}$-tetrazolium bromide, MTT reagent $(0.5 \mathrm{mg} / \mathrm{ml})$ dissolved in serum free media added to each well and incubated for $4 \mathrm{~h}$. Then, the media was aspirated and the formazan crystals were dissolved in $200 \mu 1$ of DMSO absorbance was taken at $570 \mathrm{~nm}$ in a multimode plate reader (BioTek Instruments, Synergy 4, Winooski, VT). The per cent cell inhibition in treated cells was calculated by normalizing the cells with $0 \%$ inhibition with the control group.

\section{Results}

\subsection{Characterisation of DRN}

A saturated solubility study was conducted by using different solvents. DRN was found to be more soluble in water followed by DMSO. Its solubility is less in pH 6.8 and pH 8.4 PBS solutions, these solutions are evidenced with precipitate formation. However, it is sparingly soluble in ethanol and both acids. The concentration of drug soluble in different solvents is represented in Table 1 as follows.

Table 1: Concentration of DRN soluble in different solvents

\begin{tabular}{|c|l|c|}
\hline S.No. & Name of solvent & Concentration of DRN $(\boldsymbol{\mu g} / \mathbf{m l})$ \\
\hline 1. & Distilled water & 48.45 \\
2. & DMSO & 40.73 \\
3. & Ethanol & 18.61 \\
4. & $0.1 \mathrm{M} \mathrm{HCl}$ & 20.34 \\
5. & $0.1 \mathrm{M} \mathrm{H}_{2} \mathrm{SO}_{4}$ & 15.92 \\
6. & PBS $6.8 \mathrm{pH}$ & 24.85 \\
7. & PBS $8.4 \mathrm{pH}$ & 26.19 \\
\hline
\end{tabular}

As DRN showed maximum solubility in water, it is selected as a solvent for further characterization. Žmax of DRN was found to be at $232 \mathrm{~nm}$ and the calibration curve was obtained with an $\mathrm{R}^{2}$ value of 0.993 (Figure 1). In FTIR analysis, chitosan showed peaks at $3449.16,2875.64,1651.48,1370.68 \mathrm{~cm}^{-1}$, corresponding to N-H \& $\mathrm{O}-\mathrm{H}$ stretching, $\mathrm{C}-\mathrm{H}$ asymmetric stretching, $\mathrm{C}=\mathrm{O}$ stretching of amide-I, and $\mathrm{C}=\mathrm{N}$ stretching of amide-III, respectively. STTP showed peaks at $1209.72,1126.24,916.55 \mathrm{~cm}^{-1}$, corresponding to $\mathrm{P}=\mathrm{O}$ stretching, $\mathrm{PO} 2$ symmetric and asymmetric stretching, $\mathrm{P}-\mathrm{O}-$ $\mathrm{P}$ bridge antisymmetric stretching, respectively. DRN showed peaks 
at $3313.10,2890.04,1729.31,1281.51,989.60 \mathrm{~cm}^{-1}$, corresponding to stretching vibrations of phenolic $\mathrm{O}-\mathrm{H}$ group, $\mathrm{C}-\mathrm{H}$ stretching band, $\mathrm{C}=\mathrm{O}$ stretching vibrations, and stretching bands of $\mathrm{C}-\mathrm{O}-\mathrm{C}$ groups, respectively. Whereas in a physical mixture of chitosan and STTP $3261.84,1124.31,879.65 \mathrm{~cm}^{-1}$, peaks are observed. First peak $3261.84 \mathrm{~cm}^{-1}$ corresponds to N-H \& O-H stretching of chitosan and other peaks like $1124.31,879.65 \mathrm{~cm}^{-1}$ corresponds to PO2 symmetric and asymmetric stretching and P-O-P bridge antisymmetric stretching of STTP respectively (Figure 2). Similarly, in the physical mixture of DRN, chitosan and STTP, peaks corresponding to all three compounds are shown. The peak at $3259.38 \mathrm{~cm}^{-1}$ corresponds to $\mathrm{N}-\mathrm{H} \& \mathrm{O}-\mathrm{H}$ stretching of chitosan, peak at $2974.12 \mathrm{~cm}^{-1}$ corresponds to $\mathrm{C}-\mathrm{H}$ stretching of DRN, and peak at 1124.12 and $875.77 \mathrm{~cm}^{-1}$ corresponds to PO2 symmetric and asymmetric stretching, P-O-P bridge antisymmetric stretching of STTP, respectively (Figure 3). The melting point of DRN was found to be $214^{\circ} \mathrm{C}$ after successful characterization of DRN, it is used for synthesis NPs.

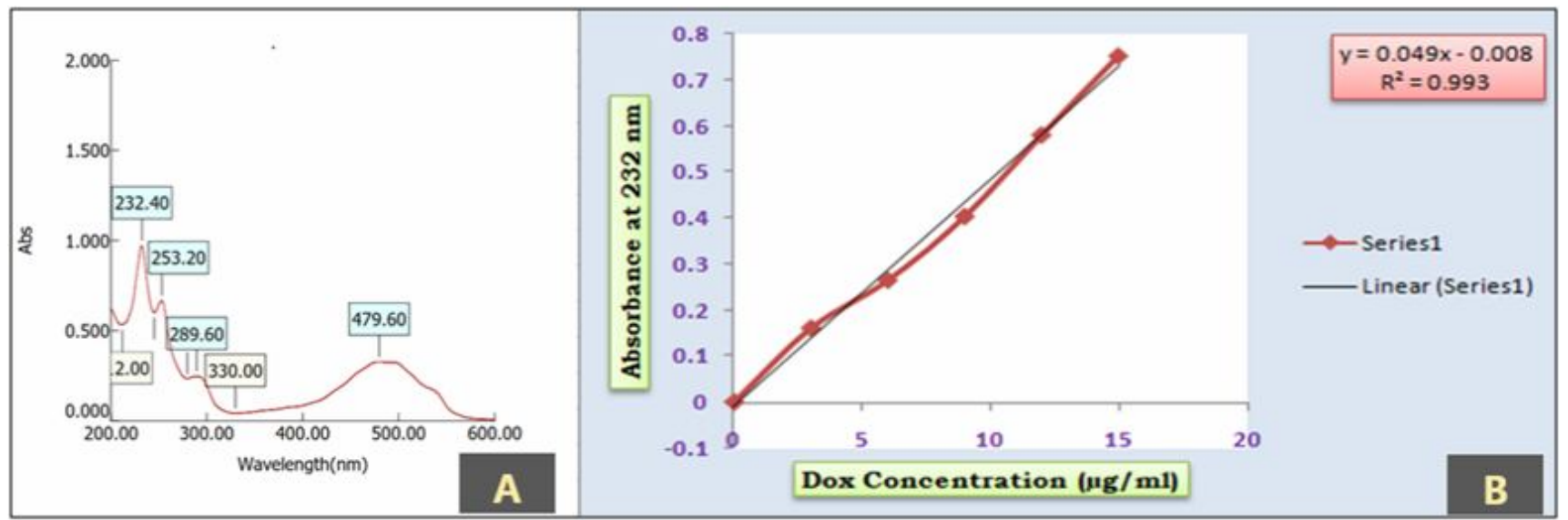

Figure 1: A-Lambda max of DRN calculated. B-Calibration curve of DRN plotted by using DRN concentration on X-axis and absorbance on Y-axis.

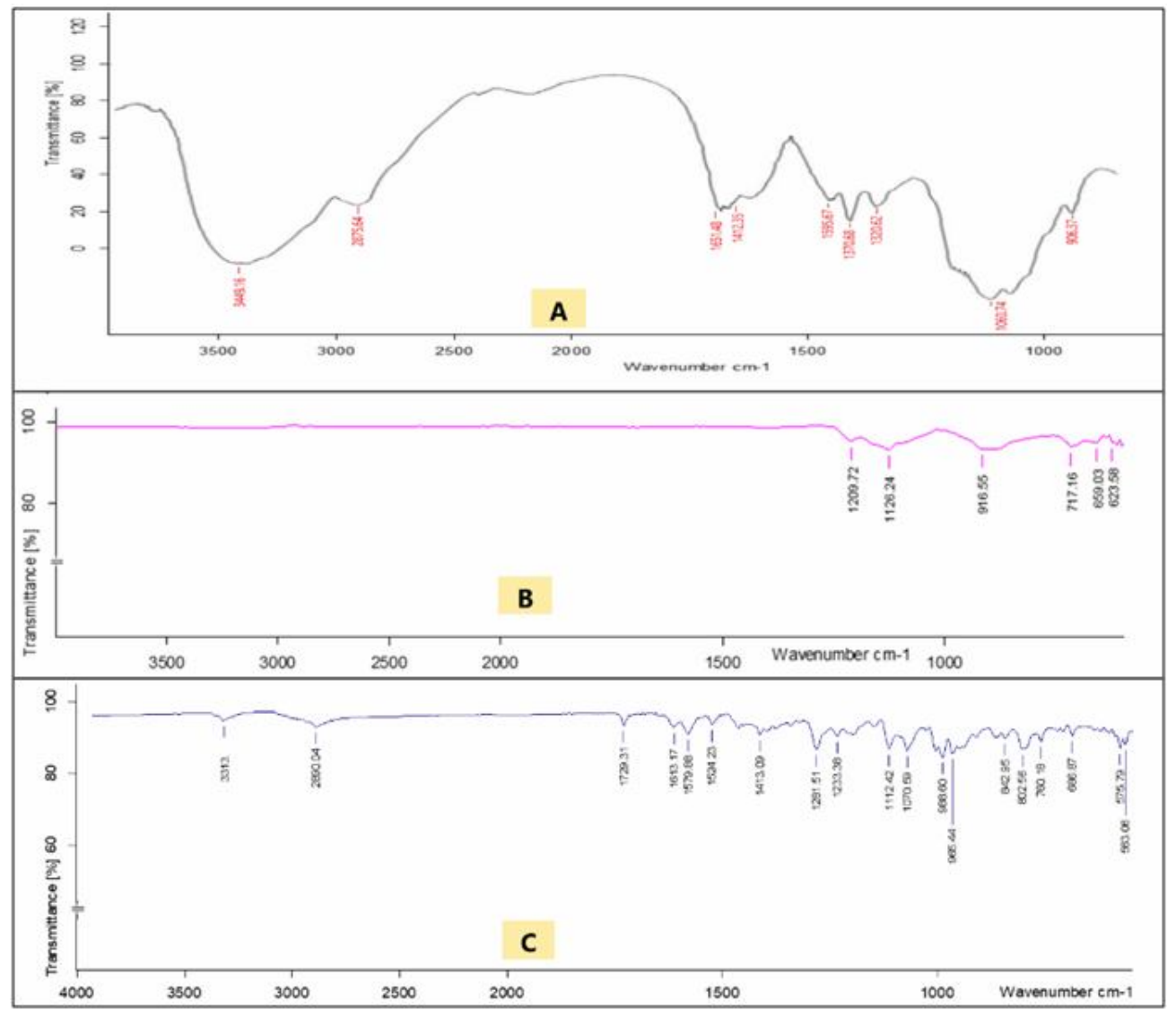

Figure 2: FTIR spectra of different compounds, A-Chitosan, B-STTP, C-DRN. 


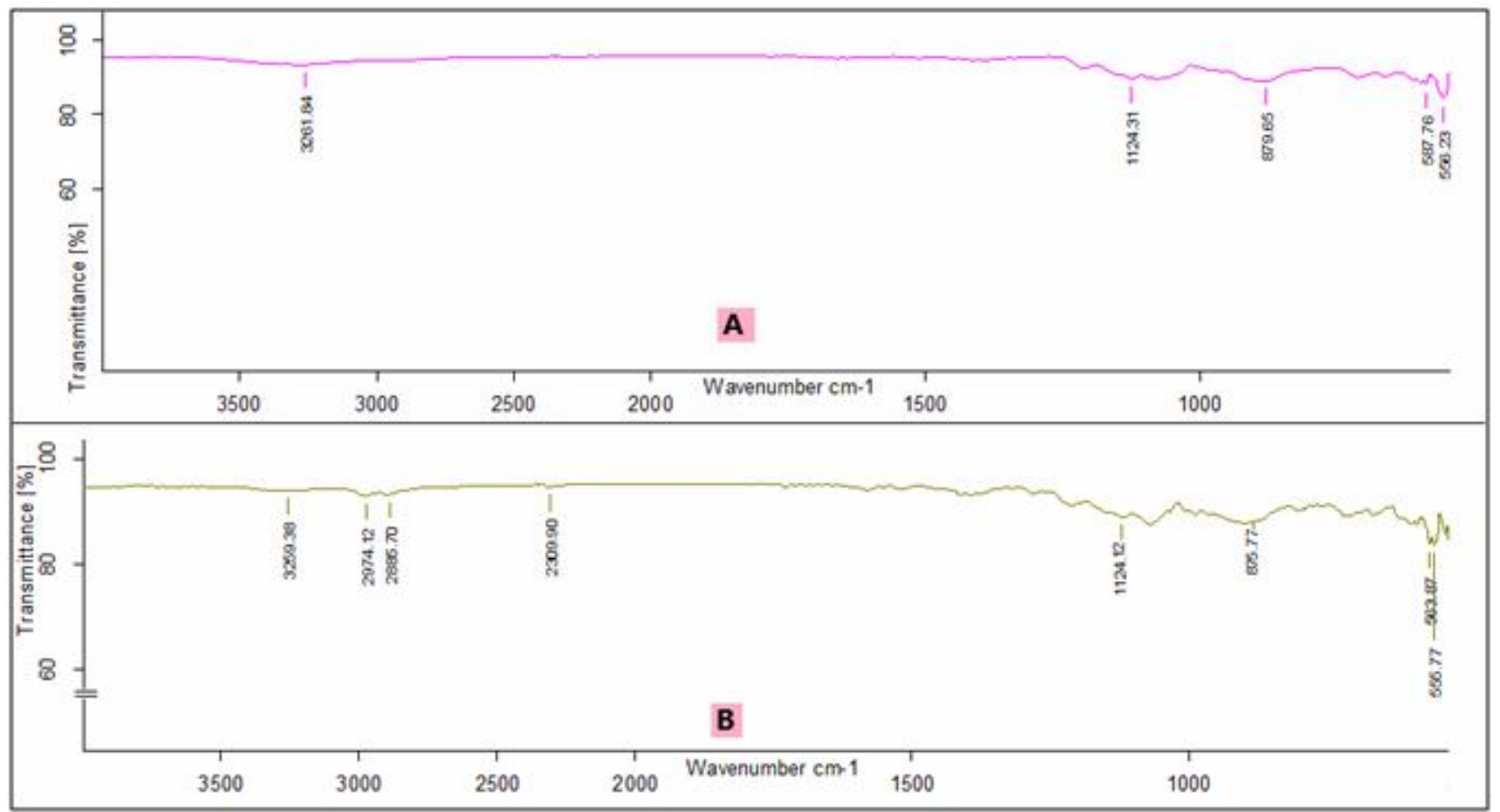

Figure 3: FTIR spectra of physical mixture of different compounds, A-Chitosan and STTP, B-DRN, chitosan, and STTP.

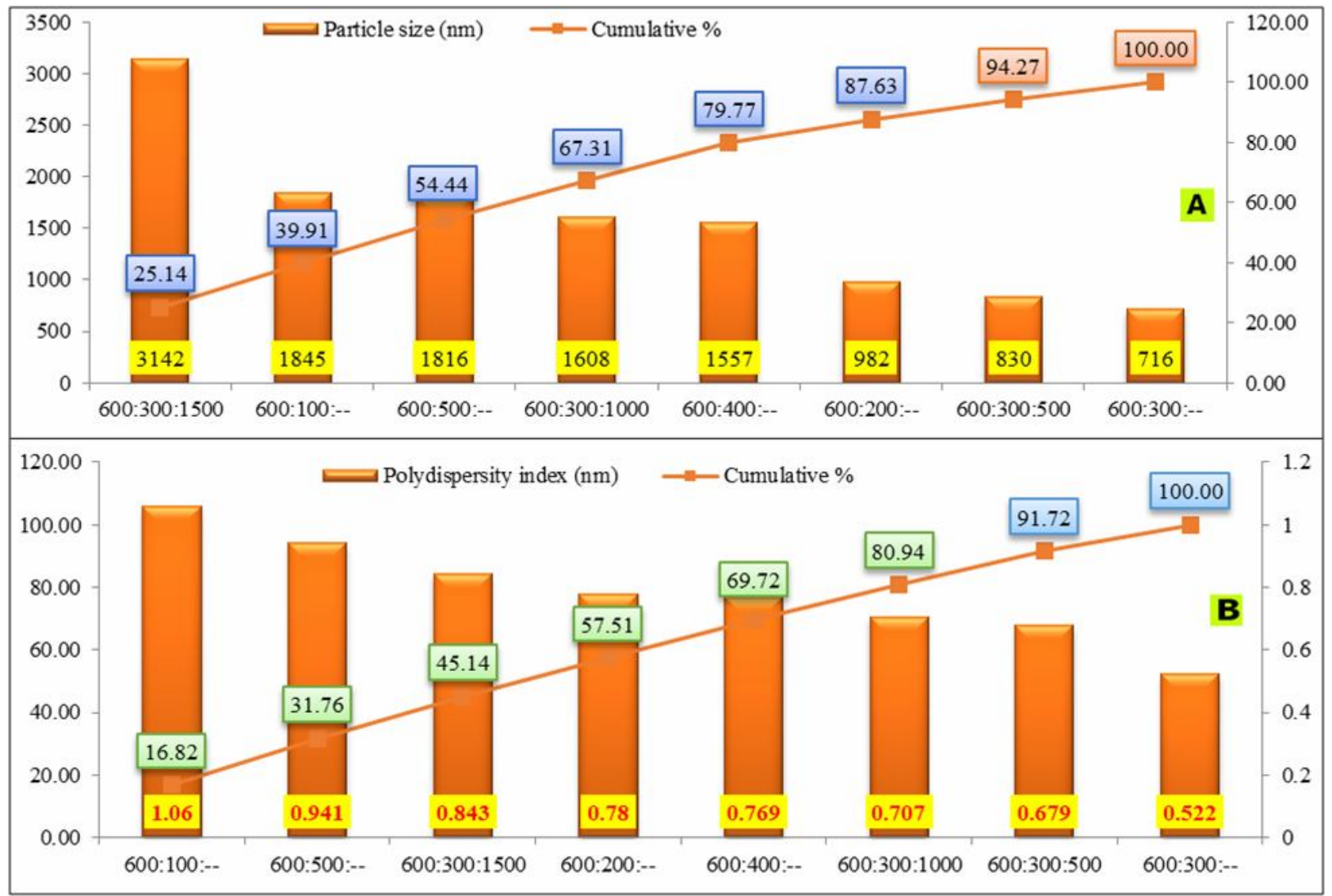

Figure 4: Pareto analysis of particle size (A) and PDI (B) of all eight formulations, formulation PLN-CNPs-3 (600:300) and DRN-CNPs-1 (600: 300:500) are selected as they are above 80 per cent. 
Table 2: Particle size, PDI, zeta potential, and EMM calculated for PLN-CNPs and DRN-CNPs

\begin{tabular}{|l|lllc|c|}
\hline Formulation & $\begin{array}{l}\text { Volume of chitosan }(\boldsymbol{\mu l}): \\
\text { STTP( } \boldsymbol{\mu l}) \text { : DRN }(\boldsymbol{\mu g} / \mathbf{m l})\end{array}$ & $\begin{array}{c}\text { Particle } \\
\text { size }(\mathbf{n m})\end{array}$ & PDI & $\begin{array}{c}\text { Zeta } \\
\text { potential }(\mathbf{m V})\end{array}$ & EMM $(\mathbf{c m}$ /Vs) \\
\hline PLN-CNPs - 1 & $600: 100:-$ & 1845 & 1.06 & -11.9 & -0.000089 \\
PLN-CNPs - 2 & $600: 200:-$ & 982 & 0.78 & -22.9 & -0.000100 \\
PLN-CNPs - 3 & $600: 300:-$ & 716 & 0.522 & -41.4 & -0.000124 \\
PLN-CNPs - 4 & $600: 400:-$ & 1557 & 0.769 & -26.1 & -0.000097 \\
PLN-CNPs - 5 & $600: 500:-$ & 1816 & 0.941 & -28.7 & -0.000112 \\
DRN-CNPs - & $600: 300: 500$ & 830 & 0.679 & 33.4 & 0.000027 \\
DRN-CNPs - 2 & $600: 300: 1000$ & 1608 & 0.707 & 24.8 & 0.000015 \\
DRN-CNPs - 3 & $600: 300: 1500$ & 3142 & 0.843 & 18.7 & 0.000009 \\
\hline
\end{tabular}
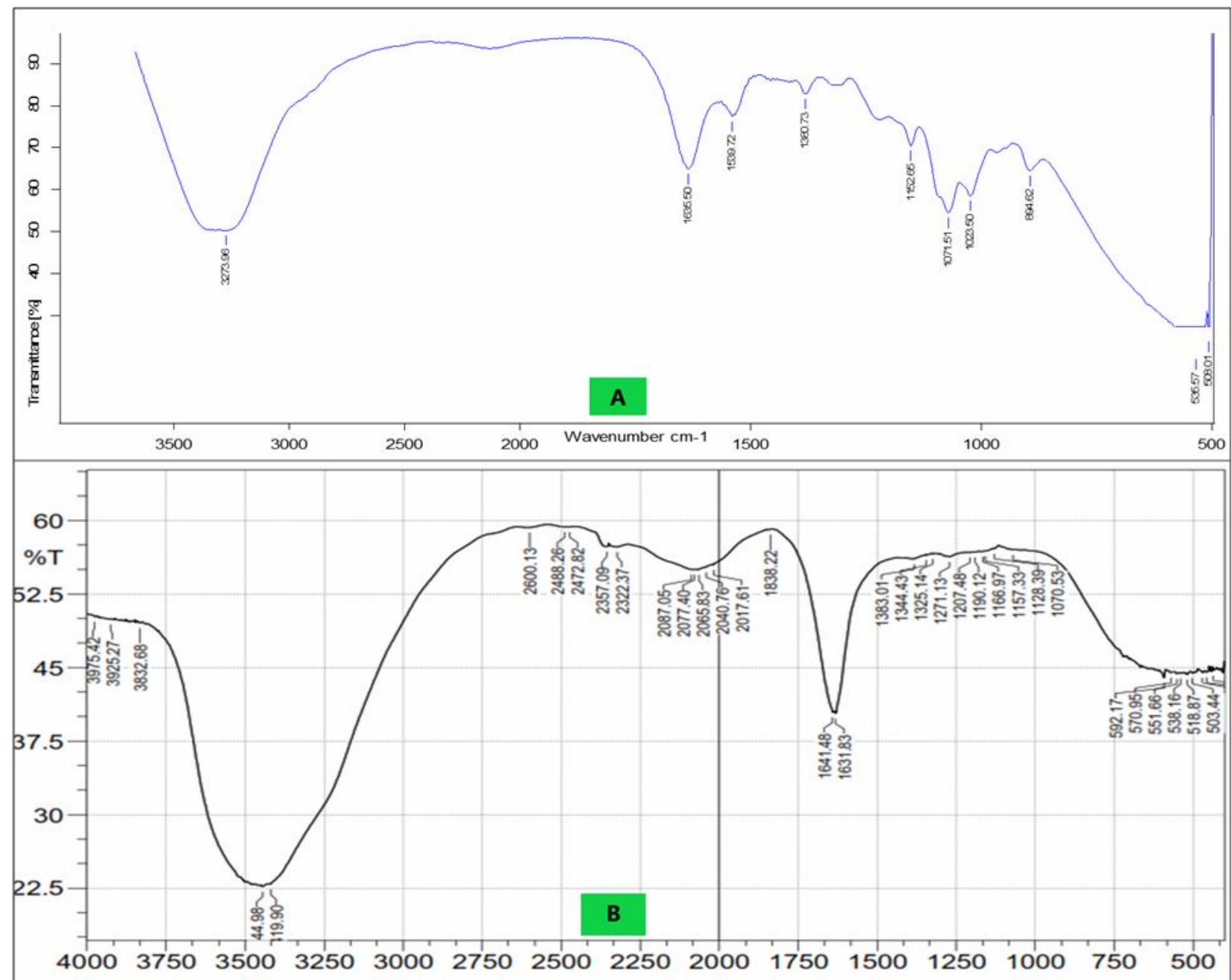

Figure 5: FTIR analysis to explore possible functional groups of various compounds. A-FTIR spectra of PLN-CNPs-3 and BFTIR spectra of DRN-CNPs-1.

3.2 Particle size, PDI, and zeta potential estimation of PLNCNPs and DRN-CNPs

To optimize the concentration of chitosan, STTP, and DRN for preparing NPs, a range of PLN-CNPs and DRN-CNPs are prepared. Among all five formulations of PLN-CNPs, PLN-CNPs-3 showed a particle size of $716 \mathrm{~nm}$ and this was increased as the volume of STTP increased in the next two formulations, i.e., PLN-CNPs 4 and 5. PDI was found to be 0.522 for the third formulation and this was found to increase in the next formulations as reported with particle size. Zeta potential and EMM were found to be $-41.4 \mathrm{mV}$ and $0.000124 \mathrm{~cm}^{2} / \mathrm{Vs}$ for PLN-CNPs-3. Both of these parameters 
increased as there was an increase in the volume of STTP added in the next formulations. Whereas DRN-CNPs are prepared with increasing concentration of DRN. As the concentration of DRN increased there was an increase in particle size and PDI and there was an increase in zeta potential and EMM. Particle size and PDI data were subjected to Pareto analysis to identify the best suited formulation for further studies. PLN-CNPs-3 and DRN-CNPs-1 were found to be the best formulations for further research (Table 2) (Figure 4).

\subsection{FTIR and SEM analysis of PLN-CNPs-3 and DRN-CNPs-1}

FTIR analysis of PLN-CNPs found to produce peaks at 3273.96, 1635.50, and $1539.72 \mathrm{~cm}^{-1}$ corresponding to $\mathrm{C}-\mathrm{O}$ indicating the presence of hydrogen bonded alcohols, $\mathrm{C}=\mathrm{C}$ Stretching indicating the presence of alkene, and $\mathrm{C}=\mathrm{C}$ absorption band, respectively. Whereas FTIR analysis of DRN-CNPs-1 was found to produce peaks at $3444.98,1641.48,1157.33,1070.53 \mathrm{~cm}^{-1}$ corresponding to $\mathrm{C}=\mathrm{O}$ stretching of amide-I indicates the presence of $\mathrm{N}$-acetyl group, $\mathrm{C}-\mathrm{O}-\mathrm{C}$ asymmetric stretching, $\mathrm{O}-\mathrm{H}$ group stretching, and $\mathrm{C}=\mathrm{O}$ stretching vibration, respectively (Figure 5).The average size of synthesized NPs was estimated by SEM. PLN-CNPs and DRNCNPs were found to get an average size (range) of 172nm (129$229 \mathrm{~nm}$ ) and $174 \mathrm{~nm}(146-194 \mathrm{~nm})$, respectively (Figure 6).

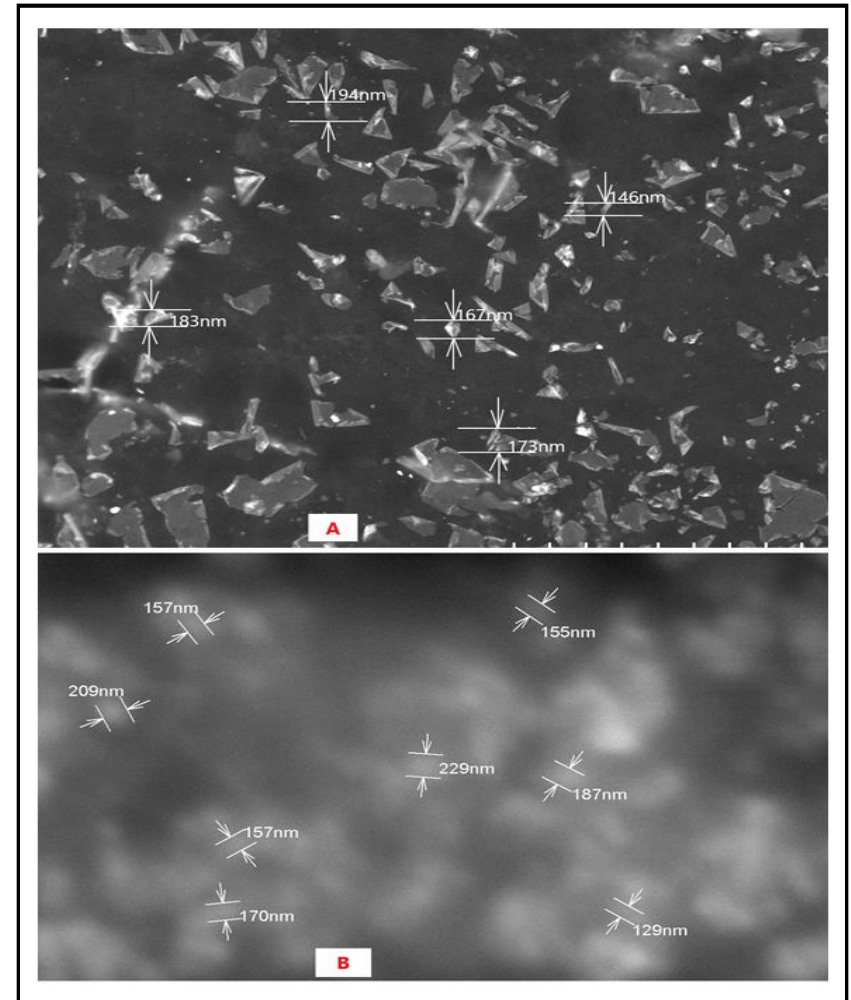

Figure 6: A-SEM image of PLN-CNPs-3, and B-SEM image of DRN-CNPs-1.

3.4 Invitro drug release, encapsulation efficiency, loading efficiency, \% yield, XRD analysis, and in vitro anticancer activity of DRN-CNPs:

DRN-CNPs are evaluated for \% release of drug at different time points as mentioned above. At $20 \mathrm{~h} 15.92 \%$ of the drug was released and it increased up to $65.47 \%$ by $100 \mathrm{~h}$ (Figure 7). Encapsulation efficiency was found to be $78.5 \%, 65.2 \%$, and $51.3 \%$ for DRNCNPs $-1,2$, and 3, respectively. Loading efficiency and \% yield of DRN-CNPs-1 were found to be $13.8 \%$ and $35.7 \%$, respectively (Table 3). Physical characteristics of DRN-CNPs were assessed by XRD technique and XRD-diffractogram is presented in Figure. $4.2 \theta$ peaks of DRN-CNPs were found to be at 28.94, 27.18, and 29.82. FWHM of these $2 \theta$ peaks was found to be $1.21,0.68$ and 0.12 . Debye-Scherrer equation was applied to calculate the average size of NPs which was found to be 30.50nm (Figure 8) (Table 4). The $\mathrm{IC}_{50}$ values against MCF-7 cell lines for DRN and DRN-CNPs1 were found to be 30.21 and 25.46 respectively. Anticancer activity was dose dependent in both treatments and DRN-CNPs-1 was found to be more effective than DRN (Figure 9).

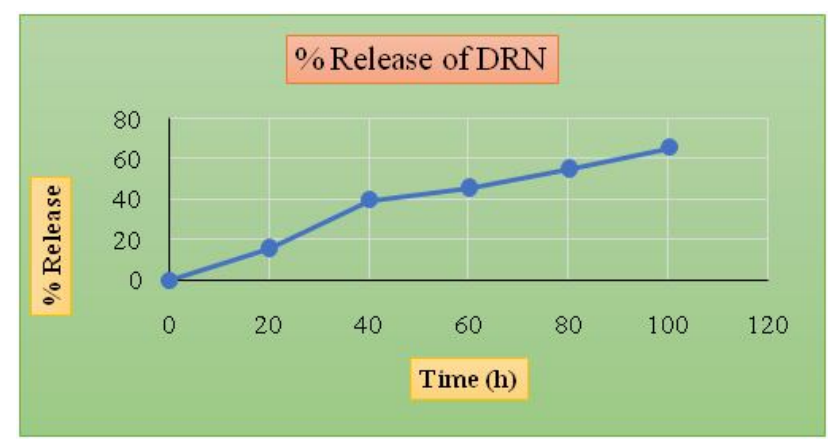

Figure 7: Percentage release of DRN from DRN-CNPs-1 at different time intervals.

Table 3: Encapsulation efficiency, loading efficiency, \% yield of different DRN-CNPs formulations.

\begin{tabular}{|l|c|c|c|}
\hline Formulation & EE\% & LE \% & \% Yield \\
\hline DRN-CNPs - 1 & 78.5 & 13.8 & 35.7 \\
DRN-CNPs - 2 & 65.2 & 11.4 & 26.3 \\
DRN-CNPs - 3 & 51.3 & 10.7 & 20.9 \\
\hline
\end{tabular}

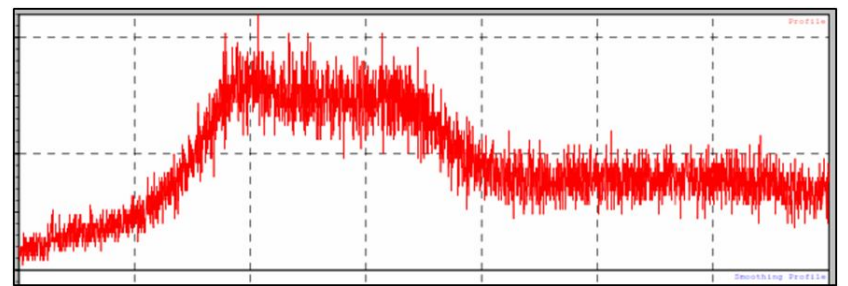

Figure 8: XRD of DRN-CNPs-1.

Table 4: $2 \theta$ peaks, FWHM, average particle size calculated from XRD of DRN-CNPs-1.

\begin{tabular}{|l|c|c|c|c|c|}
\hline $\begin{array}{l}\text { 2-theta } \\
\text { (deg) }\end{array}$ & $\begin{array}{c}\text { FWHM } \\
\text { beta } \\
\text { (deg) }\end{array}$ & (Beta) & $\begin{array}{c}\text { cos } \\
\text { theta }\end{array}$ & D & Average \\
\hline 28.945 & 1.21 & 0.021118 & 0.968268 & 7.106882897 & \\
27.18 & 0.68 & 0.011868 & 0.972002 & 12.59748624 & 30.50302 \\
29.82 & 0.12 & 0.002094 & 0.966331 & 71.80467714 & \\
\hline
\end{tabular}




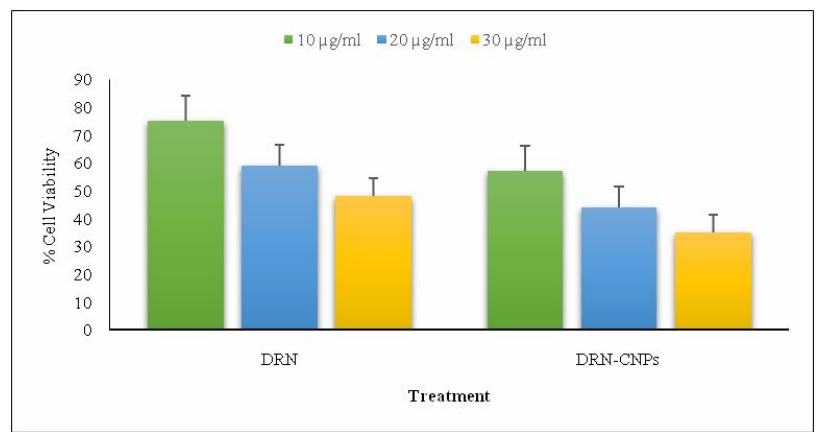

Figure 9: Percentage cell viability calculated for DRN and DRN-CNPs-1 against MCF-7 cells in MTT assay.

\section{Discussion}

Cancer remains a major challenge for mankind. Continuous research throughout the globe with all possibilities is focused to obtain complete cure and in large to decrease the annual mortality rate. Nanotechnology evolved as a boon not only to the scientific community but also to the people around the world. It is increasing the therapeutic efficacy of plant-based drugs having natural origin (Imad Uddin et al., 2019; Prairna et al., 2021; Naba et al., 2021) and also synthetic drugs having laboratory origin (Imad Uddin and Veeresh, 2020). DRN is one of the widely used anticancer drugs. It is the first option for the treatment of breast cancer. But, its usage is minimized due to increased multidrug resistance and cardiotoxicity (Mansoori et al., 2017). Drug repurposing can be achieved by addressing these problems. DRN is a red color drug with high solubility in water. By using water as a solvent, further UV-based analysis was conducted to obtain Žmax $(232 \mathrm{~nm})$. Similar results are reported with Ye et al. (2015). In FTIR analysis, functional groups reported corresponds to DRN. A peak at $1729.31 \mathrm{~cm}^{-1}$ is reported for $\mathrm{C}=\mathrm{O}$ stretching vibrations of $\mathrm{DRN}$, this characteristic peak is also reported at a very near value of $1727 \mathrm{~cm}^{-1}$ by Hami et al. (2017). DRN peaks at $1070.59 \mathrm{~cm}^{-1}$ and $842.95 \mathrm{~cm}^{-1}$ are corresponding to peaks for $\mathrm{CO}_{3}{ }^{2-}$, similar peaks (1083 and $\left.851 \mathrm{~cm}^{\prime \prime}\right)$ are earlier reported by Danmaigoro et al. (2017). The peak of chitosan at $3449.16 \mathrm{~cm}^{-1}$ corresponding to $\mathrm{N}-\mathrm{H} \& \mathrm{O}-\mathrm{H}$ stretching is also reported in the study conducted by Fernandes $e t$ al. (2015). Different peaks of chitosan, viz., 2875.64, 1651.48, $1370.68 \mathrm{~cm}^{-1}$, are other characteristic peaks. $2875.64 \mathrm{~cm}^{-1}$ is a characteristic peak of polysaccharides which is also reported in other polysaccharides (Melo-Silveira et al., 2012). Characteristic peaks of STTP reported in our study are very close to FTIR peaks reported in a study conducted by Tomaz et al. (2018). In a physical mixture of both chitosan: STTP and DRN: chitosan: STTP characteristic peaks of all in the respective drugs is shown.

Successfully characterized drugs are now used for the preparation of a range of PLN-CNPs and DRN-CNPs to optimize the suitable concentration of chitosan, STTP, and DRN. For preparing PLNCNPs volume of STTP added increased from formulation 1 to formulation 5. It was found that particle size and PDI decreased up to PLN-CNPs-3 and later on, it increased in PLN-CNPs 4 and 5. PLN-CNPs-3 showed a particle size of $716 \mathrm{~nm}$ and this was increased to $830 \mathrm{~nm}$ in DRN-CNPs-1. This increase in size is mostly due to the incorporation of DRN. A similar range of particle size for drug loaded chitosan NPs is reported in a study where 6-gingerol was used (Imad Uddin et al., 2020). PDI values are used to describe the distribution of molecular weight. So, as the concentration of DRN increased from formulation DRN-CNPs-1 to DRN-CNPs-3 there is an increase in the values of PDI indicating the broader molecular weight of formulation DRN-CNPs-3. However, an increase in particle size and high PDI are some of the disadvantages of the ionic gelation method (Das et al., 2019). The ZP, a measure of stability for formulation PLN-CNPs-3 was found to be $-41.4 \mathrm{mV}$. Thereafter in the next formulations, it was decreased up to $-28.7 \mathrm{mV}$. Whereas in the case of DRN-CNPs, ZP was decreased from formulation 1 to 3 with the highest value of $33.4 \mathrm{mV}$. These values of $\mathrm{ZP}$ indicate good stability of DRN-CNPs. As Mahobia et al. (2016) reported that values more than $+25 \mathrm{mV}$ or less than $-25 \mathrm{mV}$ have high degrees of stability. Electrophoretic mobility is measured by dividing electrophoretic velocity by electric field strength. This may be negative or positive. A negative sign indicates a moment of particles against to electrophoretic field. These values may decrease with an increase in the size of particles (Catherine, 2014). Our results are in accordance with this context, as EMM was least for PLN-CNPs-3 $(-0.000124)$ when compared to other PLN-CNPs formulations. Thus, PLN-CNPs-3 is used for the synthesis of DRN-CNPs. Among these DRN-CNPs, first formulation, i.e., DRN-CNPs-1 was found to be best suited for further studies.

In FTIR analysis, PLN-CNPs showed a single broad peak at 3273.96 $\mathrm{cm}^{-1}$. A similar peak was also reported in another study conducted by Imad uddin et al. (2020). Whereas peak found at $3444.98 \mathrm{~cm}^{-1}$ in DRN-CNP-1 was also reported in a study conducted by Songsurang et al. (2011), where authors increased delivery of DRN by formulating them in chitosan NPs. There was a shift in peaks of DRN in DRN-CNPs-1, this indicates the loading of DRN in NPs. A peak at $1641.48 \mathrm{~cm}^{-1}$ in DRN-CNPs-1 was also reported in another study where DRN was loaded in iron oxide NPs (Norouzi et al., 2020). The size of PLN-CNPs and DRN-CNPs was almost same and a similar range was reported byYousefpour et al. (2011).

Release of drug from DRN-CNPs-1 was calculated by dialysis bag method. In this method, NPs are embedded in a dialysis bag and the free drug moves out of the dialysis membrane because there is a concentration gradient of free drug between solvent inside and outside the dialysis bag (Yue et al., 2009). In a study, conducted by Zare et al. (2018), the percentage release of drug was found to be $30 \%(100 \mathrm{~h})$ at $\mathrm{pH} 7.4$, whereas in our study, release of drug was found to be $65 \%$ by $100 \mathrm{~h}$ at the same $\mathrm{pH}$ of 7.4. encapsulation and loading efficiency of DRN-CNPs-1 was found to be $78.5 \%$ and $13.8 \%$, respectively. These results depict the successful development of DRN-CNPs. Encapsulation efficiency results are very close to the results of a study conducted by Fan et al. (2018), where DRN was encapsulated for the treatment enhancement of hepatocellular carcinoma. Rouhollah et al. (2013) calculated the loading efficiency of DRN in dendrimer coated magnetic NPs as $20 \%$. Our results are also in the same pattern as this study with a loading efficiency of approximately $14 \%$. In the XRD characterization technique, successful encapsulation of DRN in NPs is studied. 2è peak of 16.75 represents DRN (Chai et al., 2017), this peak was disappeared in DRN-CNPs-1, indicating successful incorporation of DRN in NPs. These successfully characterized DRN-CNPs-1 are compared for their increased antitumor activity against unloaded DRN by using MCF-7 cell lines in MTT assay. This assay is very commonly applied to evaluate the cellular metabolic activity by measuring cell viability, proliferation and 
cytotoxicity (Riss et al., 2019). The number of cells viable is $75 \%$, $59 \%$, and $48 \%$ at DRN concentrations of 10,20 , and $30 \mu \mathrm{g} / \mathrm{ml}$. Whereas in DRN-CNPs- $1,57 \%, 44 \%$, and $35 \%$ are the percentage cell viable at 10,20 , and $30 \mu \mathrm{g} / \mathrm{ml}$. In both treatments, action produced was dose dependent and DRN-CNPs-1 was found to be more effective than DRN. Similar results are reported by Yousefpour et al. (2011). In our study, $\mathrm{IC}_{50}$ values for DRN and DRN-CNPs were found to be 30.21 and 25.46 , respectively.

\section{Conclusion}

Cancer is a leading cause of death worldwide needs emergent attention. Among various types, breast cancer is the most prevalent. DRN is commonly used for the treatment of breast cancer. But, the use of the drug is minimized due to severe adverse effects and compromised cellular availability. To increase the efficiency of DRN, the present study was conducted. Different techniques like FTIR, SEM, are used to characterize synthesized NPs. These results supported the formation of DRN-CNPs. These NPs are also tested for the percentage of drug released at $\mathrm{pH} 7.4$, encapsulation efficiency, loading efficiency, and \% yield. Results of XRD, particle size estimation, and zeta potential measurement also proved the formation of NPs. Finally, antitumor efficacy was found to be more in DRN-CNPs than unloaded DRN. The assay was conducted by using an MCF-7 cell line. This research put forth an idea to use chitosan a biocompatible polymer for loading anticancer drugs like DRN to decrease their dose dependent adverse effects and increase their efficacy.

\section{Conflict of interest}

The authors declare no conflicts of interest related to this article.

\section{References}

American Cancer Society. Cancer Treatment and Survivorship Facts and Figure 2019-2021.(2019). Atlanta: American Cancer Society. Accessed on 04-12-2021. Available from: https://www.cancer.org/content/dam/ cancer-org/research/cancer-facts-and-statistics/cancer-treatmentand-survivorship-facts-and-figures/cancer-treatment-andsurvivorship-facts-and-figures-2019-2021.pdf

Catherine, C. (2014). Chapter E-Electrophoretic Mobility. Drioli, E. and Giorno, L. (eds.). Encyclopedia of Membranes. Springer-Verlag Berlin, Heidelberg.

Chai, F.; Sun, L.; He, X.; Li, J.; Liu, Y.; Xiong, F.; Ge, L.; Webster,T.J. and Zheng, C (2017). Doxorubicin-loaded poly (lactic-co-glycolic acid) nanoparticles coated with chitosan/alginate by layer technology for antitumor applications. Int. J. Nanomedicine, 12:1791-1802.

Chatterjee, K.; Zhang, J.; Honbo, N. and Karliner, J.S. (2010). Doxorubicin cardiomyopathy. Cardiology, 115(2):155-162.

Danmaigoro, A.; Selvarajah, G.T.; Noor, M.H.M.; Mahmud, R.; Zakaria, M. and Bakar, Z.A. (2017). Development of cockleshell (Anadaragranosa) derived $\mathrm{CaCO}_{3}$ nanoparticle for doxorubicin delivery. J. Comput. Theor. Nanos., 14(10):5074-5086.

Das, S.; Singh, V.K.; Dwivedy,A.K.; Chaudhari,A.K.; Upadhyay, N.; Singh, P.; Sharma, S. and Dubey, N.K. (2019). Encapsulation in chitosan-based nanomatrix as an efficient green technology to boost the antimicrobial, antioxidant and in situ efficacy of Coriandrum sativum essential oil. Int. J. Biol. Macromol., 133:294-305.

Mahobia, S.; Bajpai, J. and Bajpai, A.K. (2016). An in vitro investigation of swelling controlled delivery of insulin from egg albumin nanocarriers. Iran J. Pharm. Res., 15(4):695.
Fan, D.; Yu, J.; Yan, R.; Xu, X.; Wang, Y.; Xie, X.; Chaolian, L.; Yonghua, L. and Huang, H. (2018). Preparation and evaluation of doxorubicin-loaded micelles based on glycyrrhetinic acid modified gelatin conjugates for targeting hepatocellular carcinoma. J. Nanomater, pp:20-29.

Fernandes Queiroz, M.; Melo, K.R.T.; Sabry, D.A.; Sassaki, GL. and Rocha, H.A.O. (2015). Does the use of chitosan contribute to oxalate kidney stone formation? Marine drugs, 13(1):141-158.

Hami, Z.; Rezayat, S.M.; Gilani, K.; Amini, M. and Ghazi-Khansari, M. (2017). In vitro cytotoxicity and combination effects of the docetaxelconjugated and doxorubicin-conjugated poly (lactic acid)-poly (ethylene glycol)-folate-based polymeric micelles in human ovarian cancer cells. J. Pharm. Pharmacol., 69(2):151-160.

Han, C.W.; De-Kuan, C. and Chia-Ting, H. (2006). Targeted therapy for cancer. J. Cancer Mol., 2(2):57-66.

Imaduddin, M.D. and Veeresh, B. (2020). Systematic review on screening the role of chemosensitizer or synergistic drug and doxorubicin as dual drug loaded nanoparticle in overcoming multidrug resistant breast cancer. Ann. Phytomed., 9(2):113-124. http://dx.doi.org/10.21276/ ap.2020.9.2.9

Imaduddin, M.D.; Rachana, N.; Suraj, N.; Naveena, N. and Mounica, P. (2019). Screening anticancer activity of colchicine loaded chitosan nanoparticles. Pharmacophore, 10(2):37-42.

Imaduddin, M.D.; Venkata Raja Srikar, P.; Preethi Karunya, Y.; Rachana, C. and Deepika, R. (2020). Synthesis and characterization of chitosan nanoparticles loaded with 6-gingerol isolated from Zingiber officinale Rosc. Ann. Phytomed., 9(2):164-171.

Mansoori, B.; Mohammadi, A.; Davudian, S.; Shirjang, S. and Baradaran, B. (2017). The different mechanisms of cancer drug resistance: A brief review. Advanced Pharmaceutical Bulletin, 7(3):339.

Melo-Silveira, R.F.; Fidelis, G.P.; Costa, M.S.S.P.; Telles, C.B.S.; Dantas-Santos, N.; Elias, S.O.; Ribeiro, V.B.; Barth, A.L.; Macedo, A.J.; Leite, E.L. and Rocha, H.A. (2012). In vitro antioxidant, anticoagulant and antimicrobial activity and in inhibition of cancer cell proliferation by xylan extracted from corn cobs. Int. J. Mol. Sci., 13(1):409-426.

Naba,J.D.; Rita, N.; Shantanu, T.;Mousumi, H.; Seema, R.P. and Surjit, M.D. (2021). Green synthesis and characterization of silver nanoparticles using leaves extract of Neem (Azadirachta indica L.) and assessment of its in vitro antioxidant and antibacterial activity. Ann. Phytomed., 10(1): 171-177.

Norouzi, M.; Yathindranath, V.; Thliveris, J.A.; Kopec, B.M.; Siahaan, T.J. and Miller, D.W. (2020). Doxorubicin-loaded iron oxide nanoparticles for glioblastoma therapy: A combinational approach for enhanced delivery of nanoparticles. Sci. Rep., 10:11292.

Othman, N.; Masarudin, M.J.; Kuen, C.Y.; Dasuan, N.A.; Abdullah, L.C.; Jamil, M. and Ain, S.N. (2018). Synthesis and optimization of chitosan nanoparticles loaded with 1-ascorbic acid and thymoquinone. Nanomaterials, 8(11):920.

Papac, R.J. (2001). Origins of cancer therapy. Yale J. Biol. Med., 74(6):391398.

Prados, J.; Melguizo, C.; Ortiz, R.; Vélez, C.; Alvarez, P.J.; Arias, J.L.; Ruíz, M.A.; Gallardo, V. and Aranega, A. (2012). Doxorubicin-loaded nanoparticles: new advances in breast cancer therapy. Anticancer Agents Med. Chem., 12(9):1058-1070.

Prairna, B.; Shruti, S. and Ahmad, Ali. (2021). Potential activities of nanoparticles synthesized from Nigella sativa L. and its phytoconstituents: and overview. J. Phytonanotech. Pharmaceut. Sci., 1(2):1-9.

Riss, T.; Niles, A.; Moravec, R.; Karassina, N. and Vidugiriene, J. (2019). Cytotoxicity Assays: In vitro methods to measure dead cells. In: Markossian, S.; Grossman, A.; Brimacombe, K.; Arkin, M.; Auld, D.; Austin, C.P.; Baell, J.; Chung, T.D.Y.; Coussens, N.P.; Dahlin, J.L.; Devanarayan, V.; Foley, T.L.; Glicksman, M.; Hall, M.D.; Haas, J.V.; Hoare, S.R.J.; Inglese, J.; Iversen, P.W.; Kales, S.C.; Lal- 
Nag, M.; Li, Z.; McGee, J.; McManus, O.; Riss, T.; Saradjian, P.; Sittampalam, G.S.; Tarselli, M.; Trask, O.J.Jr.; Wang, Y.; Weidner, J.R.; Wildey, M.J.; Wilson, K.; Xia, M. and Xu, X. editors. Assay Guidance Manual [Internet]. Bethesda (MD): Eli Lilly and Company and the National Center for Advancing Translational Sciences, 2004 .

Rouhollah, K.; Pelin, M.; Serap, Y.; Gozde, U. and Ufuk, G. (2013). Doxorubicin loading, release, and stability of polyamidoamine dendrimer-coated magnetic nanoparticles. J. Pharm. Sci., 102(6):1825-1835.

Songsurang, K.; Praphairaksit, N.; Siraleartmukul, K. and Muangsin, N. (2011). Electrospray fabrication of doxorubicin-chitosan-tripolyphosphate nanoparticles for delivery of doxorubicin. Arch. Pharm. Res. 34(4):583-592.

Tomaz,A.F.; de Carvalho, S.M.S.; Barbosa, R.C.; Silva, S.M.; Gutierrez, M.A.S.; de Lima, A.G.B. and Fook, M.V.L. (2018). Ionically crosslinked chitosan membranes used as drug carriers for cancer therapy application. Materials, 11(10):2051.

World Health Organization. Cancerfact sheet 21 september 2021 (2021). Accessed on 04-12-2021. Available from: https://www.who.int/news-room/ fact-sheets/detail/cancer

Yao, Y.; Zhou, Y.; Liu, L.; Xu, Y.; Chen, Q.; Wang, Y.; Wu, S.; Deng, Y.; Zhang, J. and Shao, A. (2020).Nanoparticle-based drug delivery in cancer therapy and its role in overcoming drug resistance. Front. Mol. Biosci., 7:193:1-14.

Ye, W.L.; Zhao, Y.P.; Li, H.Q.; Na, R.; Li, F.; Mei, Q.B.; Zhao, M.G. and Zhou, S.Y. (2015). Doxorubicin-poly (ethylene glycol)-alendronate selfassembled micelles for targeted therapy of bone metastatic cancer. Sci. Rep., 5(1):1-19.

Yousefpour, P.; Atyabi, F.; Vasheghani-Farahani, E.; Movahedi, A.A.M., and Dinarvand, R. (2011). Targeted delivery of doxorubicin-utilizing chitosan nanoparticles surface-functionalized with anti-Her2 trastuzumab. International Journal of Nanomedicine, 6:1977-1990.

Yue, P.F.; Lu, X.Y.; Zhang, ZZ; Yuan, H.L.; Zhu, W.F.; Zheng, Q. and Yang, M. (2009). The study on the entrapment efficiency and in vitro release of puerarin submicron emulsion. Aaps. Pharmscitech., 10(2):376-383.

Zare, M.; Samani, S.M. and Sobhani, Z. (2018). Enhanced intestinal permeation of doxorubicin using chitosan nanoparticles. Advanced Pharmaceutical Bulletin, 8(3):411-417.

Zhang, Y.; Yang, C.; Wang, W.; Liu, J.; Liu, Q.; Huang, F.; Chu, L.; Gao, H.; Li, C.; Kong, D.; Liu, Q. and Liu, J. (2016). Co-delivery of doxorubicin and curcumin by $\mathrm{pH}$-sensitive prodrug nanoparticle for combination therapy of cancer. Sci. Rep., 6(1):1-12. 